\title{
Severe allergic contact dermatitis due to Polysporin
}

\author{
Sophia Colantonio MD MPH, Carly Kirshen MD
}

Cite as: CMAJ 2017 August 8;189:E1018. doi: 10.1503/cmaj.161214

A healthy 28-year-old woman with a history of herpes labialis and atopic dermatitis was seen by the dermatology department after three days of substantially pruritic and edematous erythematous lip plaques with vesicles (Figure $1 \mathrm{~A}$ ), which caused difficulty in eating and drinking. She also had a vesicular eruption on her left fourth finger (supplementary Figure 2A, Appendix 1, available at www.cmaj.ca/lookup/ suppl/doi:10.1503/cmaj.161214/-/ DC1).

She had applied Polysporin

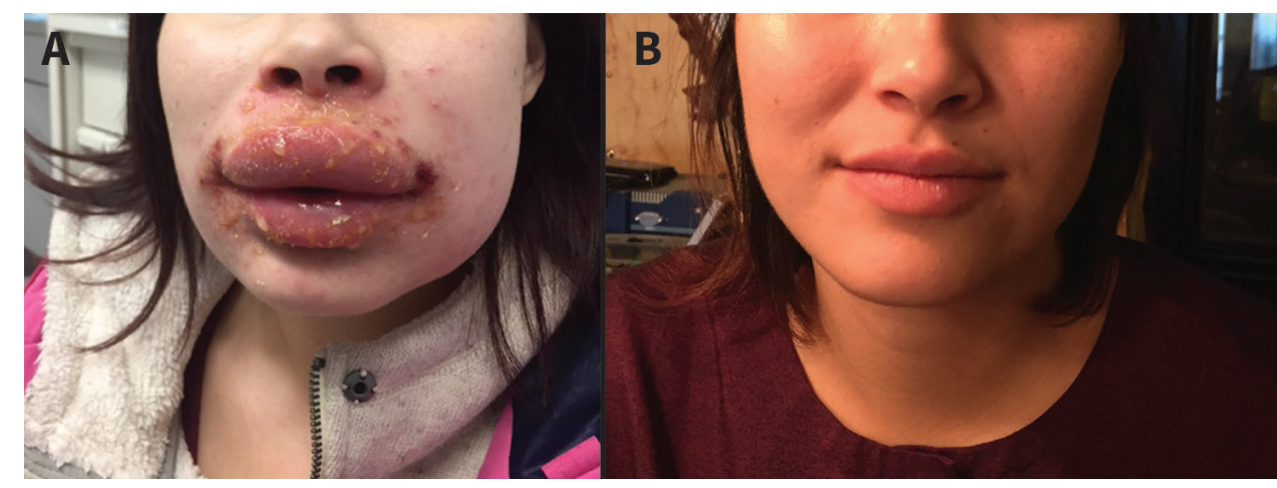

Figure 1: (A) Markedly edematous erythematous plaques with vesicles and serosanguinous exudate on the upper and lower lips of a 28-year-old woman, with associated edema of the cheeks that appeared after application of Polysporin Complete ointment. (B) Complete resolution without scarring or postinflammatory hyperpigmentation at six-month follow-up.
Complete ointment to the affected areas for several days and had used this medication previously. She had presented to a different emergency department one day before; a diagnosis of cellulitis was made, and she was treated with cephalexin taken orally.

Based on our assessment, we made a diagnosis of allergic contact dermatitis. Our differential diagnosis included irritant contact dermatitis, impetigo and angioedema. Potential allergenic ingredients included bacitracin, polymyxin B, gramicidin, lidocaine and vitamin E. We counselled the patient to avoid all Polysporin products and prescribed a three-week tapering course of high-dose prednisone taken orally and topical betamethasone valerate $0.1 \%$ ointment for her lips. She improved back to baseline (Figure 1B and supplementary Figure 2B [Appendix 1]) and had a positive result for a patch test to lidocaine.

Allergic contact dermatitis is a delayed type IV hypersensitivity reaction that requires sensitization to a chemical agent before eliciting an eczematous reaction. In its acute phase, allergic contact dermatitis presents as well-dermarcated eczematous papules and plaques that can be edematous and vesiculobullous at the site of exposure. The prevalence of allergic contact dermatitis from topical antibiotics in the general population is unknown; many cases are mild and patients do not seek care. ${ }^{1}$ A retrospective chart review involving patients at the Ottawa Hospital Patch Test Clinic showed that bacitracin and lidocaine were two of the most common allergenic medications. ${ }^{2}$
Polysporin is a popular over-the-counter topical preparation that is viewed commonly as an innocuous medication. We encourage substitution with petroleum jelly for routine care of superificial wounds, because it is as effective for wound healing as over-thecounter antibiotic preparations and does not contribute to antibiotic resistance or allergic contact dermatitis. ${ }^{3}$

\section{References}

1. Gehrig KA, Warshaw EM. Allergic contact dermatitis to topical antibiotics: epidemiology, responsible allergens, and management. J Am Acad Dermatol 2008;58:1-21.

2. Spring S, Pratt M, Chaplin A. Contact dermatitis to topical medicaments: a retrospective chart review from the Ottawa Hospital Patch Test Clinic. Dermatitis 2012;23:210-3.

3. Draelos ZD, Rizer RL, Trookman NS. A comparison of postprocedural wound care treatments: Do antibiotic-based ointments improve outcomes? J Am Acad Dermatol 2011;64:S23-9.

Competing interests: None declared.

This article has been peer reviewed.

The authors have obtained patient consent.

Affiliations: Division of Dermatology, Department of Medicine, University of Ottawa, Ottawa, Ont.

Correspondence to: Carly Kirshen, ckirs034@uottawa.ca 